\title{
BMJ Open Identifying primary care patient safety research priorities in the UK: a James Lind Alliance Priority Setting Partnership
}

\author{
Rebecca Lauren Morris, ${ }^{1}$ Susan Jill Stocks, ${ }^{1}$ Rahul Alam, ${ }^{1}$ Sian Taylor, ${ }^{1}$ \\ Carly Rolfe, ${ }^{1}$ Steven William Glover, ${ }^{2}$ Joanne Whitcombe, ${ }^{2}$ Stephen M Campbell ${ }^{1}$
}

To cite: Morris RL, Stocks SJ, Alam $\mathrm{R}$, et al. Identifying primary care patient safety research priorities in the UK: a James Lind Alliance Priority Setting Partnership. BMJ Open 2018;8:e020870. doi:10.1136/ bmjopen-2017-020870

- Prepublication history and additional material for this paper are available online. To view these files, please visit the journal online (http://dx.doi. org/10.1136/bmjopen-2017020870).

Received 28 November 2017 Revised 12 January 2018 Accepted 15 January 2018

\section{Check for updates}

${ }^{1}$ NIHR Greater Manchester Patient Safety Translational Research Centre, University of Manchester, Manchester, UK ${ }^{2}$ Trust Library Service, Manchester University NHS Foundation Trust, Manchester, UK

Correspondence to Dr Rebecca Lauren Morris; rebecca.morris@manchester. ac.uk

\section{ABSTRACT}

Objectives To identify the top 10 unanswered research questions for primary care patient safety research.

Design A modified nominal group technique.

Setting UK.

Participants Anyone with experience of primary care including: patients, carers and healthcare professionals. 341 patients and 86 healthcare professionals submitted questions.

Main outcomes A top 10, and top 30, future research questions for primary care patient safety.

Results 443 research questions were submitted by 341 patients and 86 healthcare professionals, through a national survey. After checking for relevance and rephrasing, a total of 173 questions were collated into themes. The themes were largely focused on communication, team and system working, interfaces across primary and secondary care, medication, selfmanagement support and technology. The questions were then prioritised through a national survey, the top 30 questions were taken forward to the final prioritisation workshop. The top 10 research questions focused on the most vulnerable in society, holistic whole-person care, safer communication and coordination between care providers, work intensity, continuity of care, suicide risk, complex care at home and confidentiality.

Conclusions This study was the first national prioritisation exercise to identify patient and healthcare professional priorities for primary care patient safety research. The research priorities identified a range of important gaps in the existing evidence to inform everyday practice to address primary care patient safety.

\section{INTRODUCTION}

Patient safety in healthcare is a policy priority at international, national, regional and local levels and is important to, and the responsibility of, everyone. Globally, the majority of patient contacts with healthcare occur out of hospitals in primary care, family medicine and transitional settings between providers, yet patient safety research has been done mostly in hospital settings. ${ }^{1}$ Patient safety can be defined as 'the avoidance, prevention and

\section{Strengths and limitations of this study}

- This is the first national research prioritisation exercise to identify primary care patient safety research priorities.

- More patients and/or carers submitted questions than healthcare professionals.

- The majority of questions were submitted by people over 55 and who were Caucasian despite broad promotional activities.

- The broad range of questions submitted would like require large programmes of research to address them.

- An inclusive approach to literature search and reviewing was used.

amelioration of adverse outcomes or injuries stemming from the processes of healthcare'. ${ }^{2}$ The knowledge base to inform safer care and clinical decision-making needs to be expanded to address questions that are needed in everyday clinical practice and potential strategies for system-wide improvement of care safety need to be prioritised. ${ }^{3}$ Primary care includes a number of healthcare areas including general practice, community pharmacies, dentistry, high street optometrists and others working in community settings. The nature of much of the clinical work in primary care centres on treatment uncertainties, which are often complex and not necessarily acute in nature and coordination across services, which poses many challenges to patient safety. ${ }^{45}$

Clinical research aims to improve the evidence on which decisions are made about prevention, treatment, care, management and cure while avoiding a waste of research resources. ${ }^{6}$ In the last 10 years, there has been a growth in primary care patient safety research, ${ }^{1}$ which has focused mostly on medication safety and errors. As there is 
limited time and resources available for research, it is important that priority is given to patients and healthcare professionals to address issues that affect everyday practice. ${ }^{7}$ There is an increasing recognition of the role of patients and healthcare professionals in co-setting the research agenda and the research community has been challenged to prioritise and fund research questions that are of relevance to a diverse range of stakeholders, including patients and healthcare professionals. ${ }^{8}$ The James Lind Alliance (JLA) Priority Setting Partnership (PSP) approach works with patients, carers and healthcare professionals to identify the priorities that are most important for research to address. ${ }^{9}$ There have been over 60 JLA PSPs investigating a range of treatment uncertainties, which focus on discrete clinical topics such as asthma, endometrial cancer, schizophrenia and vitiligo. ${ }^{10-13}$ This approach addresses the possible divergence between clinical research and patient priorities, which brings about the largest improvements in our knowledge of disease and service delivery. ${ }^{8}$

Involving a wider set of stakeholders in prioritising research questions may identify key areas that have not been prioritised previously by funding bodies. ${ }^{10}$ In the UK, the Department of Health funds health and care research through the National Institute for Health Research (NIHR). ${ }^{14}$ The NIHR aims to improve health through research and supports the active involvement of the public to achieve this aim. The JLA is overseen by the NIHR to support the research priorities identified through the partnerships so that they can feed directly in to national funding priorities. ${ }^{14} 15$ The Primary Care Patient Safety PSP pushed the boundaries of the JLA process by looking at unanswered questions in the diverse area of primary care, as opposed to a single clinical topic. ${ }^{416}$ The aim of the Primary Care Patient Safety PSP was to identify unanswered research questions in the field of primary care patient safety research and to identify the top research priorities for primary care patient safety from patients, carers and primary care healthcare professionals.

\section{METHOD}

This study followed the JLA methodology. ${ }^{9}$ This project was led and funded by the NIHR Greater Manchester Primary Care Patient Safety Translational Research Centre (Greater Manchester PSTRC) which is a partnership between Salford Royal National Health Service (NHS) Foundation Trust and The University of Manchester working with clinical and patient partner organisations. Partner organisations included representatives from the Royal College of General Practitioners, Royal College of Nursing, British Dental Association, Healthwatch Manchester, Carers UK, The Patients Association, Pharmacy Voice, NHS Salford Clinical Commissioning Group, Royal Pharmaceutical Society, and the Lesbian, Gay, Bisexual and Trans (LGBT) Foundation. The JLA provided an independent chair, advised on methodology and facilitated the final prioritisation setting workshop. ${ }^{9}$

\section{Stage 1: initiation}

Steering group set-up

The first stage involved identifying potential partner organisations to be members of the steering group to direct the project as well as having access to a wide range of potential participants to submit questions and reflected the diversity of people who work and/or use primary care services. The steering group included representatives from the Royal College of Nursing, the British Dental Association, the Royal College of General Practitioners, Healthwatch Manchester, Carers UK, the Patients Association, Pharmacy Voice, NHS Salford Clinical Commissioning Group, Royal Pharmaceutical Society and LGBT Foundation. The steering group was responsible for from agreeing the initial focus, publicising the PSP, overseeing and collating the priorities as well as taking the final priorities to research funders. ${ }^{9}$

\section{Project initiation and eligibility}

Anyone living in the UK who uses primary care services, carers or who are healthcare professionals in primary care were eligible to participate in the identification and prioritisation of uncertainties. Non-clinical researchers and employees of pharmaceutical or medical devices companies were excluded from the survey. ${ }^{9}$ A website (http:// research.bmh.manchester.ac.uk/PatientSafetyPSP) was created to advertise the partnership and the online survey.

\section{Stage 2: gathering 'uncertainties'}

The first consultation was conducted via an electronic questionnaire with paper copies available on request (online supplementary material 1). Participants were asked "What are your questions about primary care (general practice, pharmacy, dentistry) patient safety?" and a short demographic survey available through the PSP website (the full survey is available as online supplementary material). The questionnaire was open from 1 June to 13 July 2016. Participants were recruited via a range of convenience sampling in line with the aim of the JLA approach which promotes that the process is as inclusive as possible of patient and healthcare professional views. ${ }^{9}$ The steering group members and the Greater Manchester PSTRC promoted the survey through a range of newsletters to members, social media, and through professional and patient networks.

\section{Stage 3: analysis and verification of uncertainties}

The submitted questions were grouped into key themes. Questions were then analysed to identify duplicates and indicative questions were created when there were multiple questions submitted that asked similar questions. Duplicate questions, comments or questions outside the scope of the PSP were removed. RLM led the identification of the indicative questions with initial discussion with SMC and SJS. The steering group then reviewed the indicative questions, and questions identified as duplicate or out 
of scope which had been removed, alongside the initial submitted questions to confirm the final question set maintained the intent of the initial submitted questions. Every question was then searched against the existing literature. The literature was searched by an independent group of health information specialists led by SWG and JW from Trust library service, Manchester University NHS Foundation Trust used a predefined systematic criteria. Analysis of the search results was completed by RLM and RA. A question was considered to have met the certainty criteria if a recent (within 5 years) systematic review concluded that there was sufficient evidence to answer the question. ${ }^{11} 17$

\section{Stage 4: interim prioritisation}

The steering group ranked the questions via an online survey where questions were presented to each member in a random order to reduce bias. The top 60 questions were then taken to a second national survey. The second survey was open from 13 January to 24January 2017. Patients, carers and healthcare providers were invited to rank the importance of each of the questions for primary care patient safety research from 'very important' to 'very unimportant.' To reduce bias questions were presented in a random order to each participant.

\section{Stage 5: final prioritisation workshop}

The top 30 questions ranked as the most important were taken forward to a final prioritisation workshop which was a face-to-face consensus meeting held on the 16 March 2017. Steering group members, volunteers from partner organisations, patients and carers were recruited through networks to take part in the final workshop. Attendees were divided into three equal-sized groups with a mix of healthcare professionals, patients and carers. The groups were asked to rank the questions through guided discussion facilitated by three independent JLA advisors. The rankings were then collated and the groups mixed and then ranked the questions a second time. The aggregate ranking from the small group exercise was then taken forward to a whole group discussion where the final order of question priority was agreed. The final top 10 most important unanswered questions in primary care patient safety were agreed by the full group (figure 1).

\section{Patient involvement}

Patients were involved in the study as members of the steering group as representatives of patient groups. Patient steering group members, along with other steering group members, directed the study, develop and agree the scope of the PSP, recruitment of patients as representatives of patient groups, reviewing and agreeing indicative questions, ranking of questions and in all stages of the prioritisation and dissemination processes through advertising the survey and its results to their networks.

\section{RESULTS}

\section{Question gathering}

Four hundred and forty-eight participants answered all or part of the initial national free-text survey with 237 people submitting 443 questions (see figure 1). Three hundred and forty-one questions were submitted by patients or carers (table 1). The initial survey yielded 9124 views. One hundred and eighty-two submissions either did not include a question or stated that they did not have a question about primary care patient safety $(n=144)$ or did not understand the question $(n=38)$. From the remaining 270 submissions, 443 individual research questions were identified.

\section{Analysis and verification of uncertainties}

Forty-six questions were excluded as outside of the scope of the PSP; for example, a request for research in stem cell research. The remaining 397 questions were then grouped into themes. The key themes identified were medication $(n=50)$, diabetes care $(n=46)$, access $(n=32)$, education and training $(n=29)$, communication $(n=28)$, patient records $(n=14)$, workforce and capacity $(n=13)$, continuity of care $(n=10)$, governance $(n=9)$, multimorbidity $(n=7)$, foot care $(n=7)$, reception $(n=6)$, harm $(n=6)$, out of hours care $(n=6)$, patient awareness of patient safety $(n=6)$, hygiene $(n=6)$ (for all topic themes see table 2).

Questions focused on primary care broadly $(n=240)$, general practice $(\mathrm{n}=95)$, patient-level self-management $(n=30)$, pharmacy $(n=14)$, out of hours care $(n=6)$, patient and public involvement in research $(\mathrm{n}=2)$ and physiotherapy $(\mathrm{n}=1)$.

Indicative questions were created from duplicate entries and narrative submissions so that they kept the original meaning of the submission, leaving 216 questions to be verified against the existing literature evidence. All indicative questions were agreed by the steering group. In total, 173 questions were considered unanswered by research.

\section{Interim prioritisation}

The 60 most important unanswered research questions were then prioritised by a second national online survey completed by 447 people, including 374 patients or carers (online supplementary material 2). The top 30 questions that were ranked as most important were taken forwards to the final consensus meeting (see table 3 for ranking by patients and healthcare professionals).

\section{Final prioritisation}

A mixed group of 22 stakeholders discussed and ranked the final 30 questions at a final face-to-face meeting (13 patients or carers, 3 GPs, 5 pharmacists and 1 nurse). The discussions were facilitated by independent JLA facilitators. ${ }^{9}$ The top 10 questions were agreed by all stakeholders as the most important unanswered questions (see table 4). 
Establish steering group with partner organisations (March 2016)

10 organisations became partners

Steering group define and agree scope for Priority Setting Partnership

Identify research 'uncertainties': online survey (May-July 2016)

443 initial questions submitted

71 from professionals

341 from patients

Classify, refine, remove duplicates or out of scope questions, and create indicative questions (July-September 2016)

216 potential uncertainties identified

Literature reviews October-December 2016

173 uncertainties remained for prioritisation

Shortlisting by steering group (December-January 2016)

top 60 questions prioritised by steering group members

National prioritisation exercise: second online survey (January-February 2016)

Top 30 ranked from weighted and ranked vote taken to final priority by 457 people ( 67 professional, 374 patients and carers, 16 other)

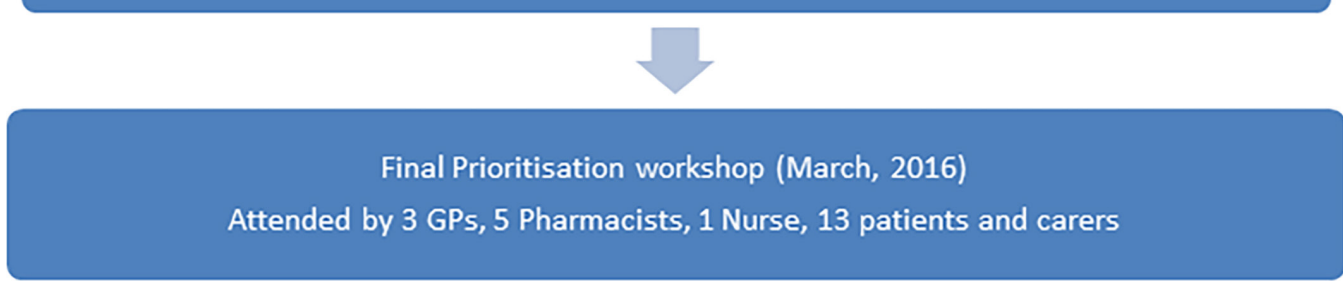

Figure 1 Summary of the James Lind Alliance Priority Setting Partnership. GPs, general practitioners.

\section{DISCUSSION}

This study has identified the limited evidence available currently to address some key questions and priorities about patient safety in primary care. Of 270 questions submitted, 173 unique questions were identified for prioritisation. The top 10 research priorities (see table 4) included how patient safety can be assured for the most vulnerable in society, taking holistic approaches to care, transitions and communication of care between primary and secondary care, staffing issues, continuity of care, communication between patients and care providers, identifying and support people at risk of suicide, the appropriateness of different practitioners for different types of clinical work, accessing patient medical records and safe care at home. The questions incorporated understanding existing concepts and challenges (eg, continuity of care, holistic care and communication) with emerging issues and widening the focus of patient safety priorities (eg, safer care at home or patients accessing their medical records). ${ }^{18-21}$ These results will be used by funders and researchers to identify future research priorities that are most relevance to patients and healthcare professionals in an attempt to address this lack of evidence to support patient and healthcare professional 
Table 1 Participant demographics

\begin{tabular}{|lrc|}
\hline & $\begin{array}{l}\text { First } \\
\text { survey }\end{array}$ & $\begin{array}{l}\text { Second } \\
\text { survey }\end{array}$ \\
\hline Participant characteristic & 341 & 373 \\
\hline Patient or carer & 86 & 51 \\
\hline Healthcare professional & 3 & 1 \\
\hline Preferred not to say & 3 & 19 \\
\hline Other & 5 & 3 \\
\hline Left blank & & \\
\hline Age & 4 & 5 \\
\hline 16-24years & 25 & 43 \\
\hline 25-34years & 38 & 45 \\
\hline 35-44years & 62 & 86 \\
\hline $45-54$ years & 87 & 117 \\
\hline 55-64years & 75 & 115 \\
\hline $65-74$ years & 20 & 30 \\
\hline 75 and over & 1 & 3 \\
\hline Prefer not to say & 6 & 3 \\
\hline Left blank & & \\
\hline
\end{tabular}

\section{Ethnicity}

\begin{tabular}{lcc}
\hline Arab & 1 & 1 \\
\hline Asian or Asian British: Indian & 7 & 5 \\
\hline Asian or Asian British: Chinese & 3 & 0 \\
\hline Asian or Asian British: Other & 1 & 1 \\
\hline Asian or Asian British: Pakistani & 2 & 3 \\
\hline Black or Black British: Caribbean & 4 & 1 \\
\hline Black or Black British: African & 2 & 0 \\
\hline Black or Black British: Other & 1 & 0 \\
\hline Prefer not to say & 7 & 8 \\
\hline Scottish & 0 & 1 \\
\hline White & 411 & 412 \\
\hline White English & 0 & 1 \\
\hline White and Asian & 1 & 3 \\
\hline White and Black African & 1 & 2 \\
\hline White and Black Caribbean & 1 & 2 \\
\hline White and North African & 0 & 1 \\
\hline White British & 0 & 1 \\
\hline Other & 2 & 0 \\
\hline Missing & 2 & 5 \\
\hline Gender & & \\
\hline Female & 225 & 237 \\
\hline Male & 218 & 202 \\
\hline In another way & 1 & 0 \\
\hline Prefer not to say & 0 & 5 \\
\hline Geft blank & 4 & 3 \\
\hline No & 3 & 1 \\
\hline
\end{tabular}

Continued
Table 1 Continued

\begin{tabular}{lcc}
\hline & $\begin{array}{l}\text { First } \\
\text { survey }\end{array}$ & $\begin{array}{l}\text { Second } \\
\text { survey }\end{array}$ \\
\hline Yes & 427 & 434 \\
\hline Prefer not to say & 0 & 5 \\
\hline Left blank & 7 & 7 \\
\hline Did not understand the question & 1 & 0 \\
\hline $\begin{array}{l}\text { Sexual orientation } \\
\text { Lesbian or gay }\end{array}$ & 13 & Unknown \\
\hline Bisexual & 6 & Unknown \\
\hline Heterosexual & 392 & Unknown \\
\hline Other & 3 & Unknown \\
\hline Prefer not to say & 15 & Unknown \\
\hline Left blank & 19 & Unknown \\
\hline
\end{tabular}

everyday questions about patient safety in primary care and research activity.

The limited evidence to support patients and healthcare professionals to inform primary care service design and delivery is important given the growing priority of patient safety both nationally and internationally. ${ }^{22}$ While the focus of this PSP was within the UK, the top 10 uncertainties reflect many universal commonalities addressing patient safety in care delivery and management (such as staffing issues, communications and transitions between care settings) that are of relevance internationally and for which there are limited tools or strategies to measure, monitor and improve patient safety; for example, diagnostics and transitions of care. ${ }^{1}$ The fact that the number one priority was about understanding patient safety for the most vulnerable in society is particularly relevant given that this includes people where there has traditionally received less research focus. ${ }^{23}$ Furthermore, the recognition of treating the patient as a whole person, rather than focusing on individual conditions, is of particular relevance given that many of the guidelines and support available has focused on individual conditions (eg, in the UK the National Institute for Health and Care Excellence ${ }^{24}$ ) and do not address the everyday decisions and prioritisations that patients and healthcare professionals must make when faced with multiple conditions and treatment options. $^{2526}$

Communication and care coordination was a focus of many questions that were submitted, despite the fact that there is a large body of research in these areas and these issues. In addition, a focus on holistic care is not a new priority with personal and holistic care having been advocated for many years, ${ }^{27}$ suggesting that in an ever more complex and digital era of medicine, personal care remains of importance. It suggests also that there remains a gap between rhetoric and reality. ${ }^{28}$ It is still not understood clearly how these issues are conceptualised and understood from a patient safety perspective; for example, continuity of care. ${ }^{29}$ This suggests that there 
Table 2 Topic themes of submitted questions

\begin{tabular}{|c|c|}
\hline Topic theme & $\begin{array}{l}\text { Number of } \\
\text { questions submitted }\end{array}$ \\
\hline Medication & 50 \\
\hline Diabetes care & 46 \\
\hline Access & 32 \\
\hline Education and training & 29 \\
\hline Communication & 28 \\
\hline Patient records & 14 \\
\hline Workforce and capacity & 13 \\
\hline Continuity of care & 10 \\
\hline Governance & 9 \\
\hline Multimorbidity & 7 \\
\hline Foot care & 7 \\
\hline Reception & 6 \\
\hline Harm & 6 \\
\hline Out of hours care & 6 \\
\hline Patient awareness of patient safety & 6 \\
\hline Hygiene & 6 \\
\hline Interface & 5 \\
\hline Blood tests & 5 \\
\hline Diagnosis & 5 \\
\hline Treatment & 5 \\
\hline NICE guidance & 4 \\
\hline Dispensing & 4 \\
\hline Appointment time & 3 \\
\hline Disability & 3 \\
\hline Information & 3 \\
\hline Long-term condition management & 3 \\
\hline Pain & 3 \\
\hline Risk assessment & 3 \\
\hline Multidisciplinary teams & 2 \\
\hline Holistic views of patients & 2 \\
\hline Understanding patient safety & 2 \\
\hline $\begin{array}{l}\text { Implementation of research or } \\
\text { guidelines }\end{array}$ & 2 \\
\hline Coordination of care & 2 \\
\hline Confidentiality & 2 \\
\hline Cost of safety & 2 \\
\hline Intervention development & 2 \\
\hline Knowledge & 2 \\
\hline Mental health & 2 \\
\hline Annual follow-up & 2 \\
\hline Patient experience & 2 \\
\hline Medical errors & 2 \\
\hline Identifying people at risk of suicide & 1 \\
\hline Care Quality Commission & 1 \\
\hline
\end{tabular}

Continued
Table 2 Continued

Topic theme

Number of questions submitted

Definition of patient safety

1

Dementia

Diet 1

NHS changes 1

Dental infection

Condition awareness

Consultation

Contextual approaches to safety

Errors

Geographical differences

Health and social care development

Impact of patient safety awareness 1

Integrated approach to safety 1

Locum doctors

Minor injuries

Models of care

1

Obesity

Patient engagement with healthcare 1

Palliative care

Patient role in safety

Physical safety

Polypharmacy

Population versus personalised care

Patient and public involvement

Prescription

Prevention of issues

Priorities

Quality improvement

Referrals

Regional care

Resources

Review appointments

Safety boundaries

Safety causing other issues

Safer care at home

Service changes

Technology

Test results

Transferability of patient safety

initiatives

Violent patient management

Yellow Card scheme

1

NHS, National Health Service; NICE, National Institute for Health and Care Excellence. 
Table 3 Ranking of top 30 questions (final and preworkshop)

\section{Question}

$\begin{array}{ll}\text { Final rank } & \begin{array}{l}\text { Overall rank } \\ \text { (prefinal }\end{array} \\ \text { postworkshop } & \text { workshop) }\end{array}$

Rank preworkshop Rank preworkshop

postworkshop workshop)

\section{(by patients or} carers) by healthcare professionals

How can patient safety be assured for the most vulnerable in society (eg, people who are frail, have mental health problems or 1 cognitive impairments)?

How can we make sure that the whole patient is treated, not just 2 one condition and with mental health and physical health both being treated together?

$3 \quad 3$

2

How can we improve safe communication and coordination of care between primary and secondary care?

In what ways does work intensity, hours worked and staffing levels 4 affect patient safety/near misses?

How does continuity of care influence patient safety?

patients understand the information that has been conveyed to them during the consultation?

What can primary care do to identify and support people who may 7 be at risk of suicide?

Which type of practitioner (general practitioner (GP), advanced 8 nurse practitioner, practice nurse) is safest to see which types of patients (acute illnesses, acute on chronic multimorbid)?

3

$\begin{array}{lll}7 & 9 & 3\end{array}$

6

11

11

22

6 7 9 8

6

How can information within patient medical records be made available to patients and care providers in a way that protects privacy and improves safety and quality of care?

9

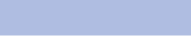

5

6

8

8

$\begin{array}{lll}22 & 21 & 29\end{array}$

How can risks be mitigated to allow for safe complex care at home?

10

Are difficulties in contacting doctors and/or making appointments 11 associated with more delays or errors in diagnosis or other failures of care?

How many patients actually know what medication they are

12 taking, what for and what the potential side effects are?

What can be done to improve access to GP surgery for someone 13 with mental health problems?

13

How can communication between healthcare professionals be 14 improved for people with multiple long-term conditions?

14

8

25

18

How safe is treatment in out of hours care if patient notes are not 15 available?

15

(25)

2

8

13

What do patients understand about when they should or should not contact a GP and who they should see instead?

16

4

2

2

4

5

7

24

How can we encourage patients and clinicians to be more open about patient safety incidents within a culture of learning rather than blame?

17

18

care?

12

17

What is the role of the receptionist in patient safety, that is, facilitating access to urgent appointments?

19

How well trained are receptionists as acting as gatekeepers to 20

GPs and prioritising patients?

20

26

24

42

How can GP practices appointment systems (eg, telephone, online) be improved?

21

What types of prescribing errors are occurring in GP prescribing 22 practice and how often are they occurring?

22

13

10

27

31

11

How do GPs inform their patients of the side effects and potential 23 risks when prescribing a new medication?

21

$\begin{array}{rrr}21 & 19 & 35 \\ 18 & 20 & 21 \\ 6 & 4 & 26\end{array}$

How are medical errors in primary care prevented and recorded? 24

Do GP practices keep patient records up to date to ensure safety 25 when a patient is seen by a different GP? 
Table 3 Continued

\begin{tabular}{llll}
\hline Question & $\begin{array}{l}\text { Final rank } \\
\text { postworkshop }\end{array}$ & $\begin{array}{l}\text { Overall rank } \\
\text { (prefinal } \\
\text { workshop) }\end{array}$ & $\begin{array}{l}\text { Rank preworkshop Rank preworkshop } \\
\text { (by patients or } \\
\text { carers) }\end{array}$ \\
\hline $\begin{array}{l}\text { Why is there such a time lag between seeing the hospital } \\
\text { consultant and the GP getting information about a medication } \\
\text { professionals }\end{array}$ & 26 & 16 & 17 \\
$\begin{array}{l}\text { change? } \\
\text { How frequent are the misdiagnosis of symptoms by GPs resulting } \\
\text { in patient safety incidents? }\end{array}$ & 27 & 14 & 14 \\
$\begin{array}{l}\text { Do GPs and other healthcare professionals record patients who } \\
\text { are vulnerable/at risk in the patient notes? }\end{array}$ & 28 & 16 \\
$\begin{array}{l}\text { Does seeing a named GP who knows an individual have safer care } \\
\text { than seeing a GP who does not know me? }\end{array}$ & 17 & 18 \\
\hline $\begin{array}{l}\text { Do the actions of receptionists have potential ramifications for } \\
\text { patient safety? }\end{array}$ & 30 & 19 & 23 \\
\hline
\end{tabular}

remain unanswered questions about how to implement research into practice and potentially the impact, or awareness, of research to inform policy, commissioning and clinical practice. ${ }^{82230}$ While research exists in part to address some of these questions, ${ }^{31}$ there remains an imbalance of research evidence across primary care professions that responds to the context in which decisions are being made by different professionals (eg, dentists, pharmacists, practice nurses) and a lack of strong evidence, improvement studies or replication studies to support these decisions. $^{32}$

\section{Strengths and limitations of the study}

This was a large national prioritisation exercise with 341 patients and/or carers, and 94 healthcare professionals submitting questions and the priorities identified unanswered question which are of relevance across the UK. The imbalance of submissions between patients and healthcare professional was noticeable given the targeted approach by representatives of primary healthcare professional groups and professional networks. Adverts were sent to members of various organisations including patient support groups, members of professional organisations as well as through Twitter and other non-specific targeted adverts. However, there was limited involvement by some healthcare professional groups, such as ophthalmologists, care homes and social work sectors as there were no organisations representing this group on the steering group as membership of the steering group was a balance between being inclusive while being a manageable size. Further PSPs could work with members from these communities to examine in detail patient safety within these diverse settings. Furthermore, despite working with the LGBT foundation there were fewer questions submitted by members of this community. Although this process is unlikely to be representative given that certain groups maybe more active and more likely to submit questions, this is mitigated by the process of creating indicative questions for similar submissions and the prioritisation exercises meaning that the final top 10 questions were from the full range of submissions reflecting patient and healthcare professional priorities. Furthermore, while participants were asked to identify if they lived in the UK, we did not ask which region they were located in and it is possible that one geographical location, for

\begin{tabular}{|c|c|}
\hline 1 & $\begin{array}{l}\text { How can patient safety be assured for the most vulnerable in society (eg, people who are frail, have mental health } \\
\text { problems or cognitive impairments)? }\end{array}$ \\
\hline 2 & $\begin{array}{l}\text { How can we make sure that the whole patient is treated, not just one condition and with mental health and physical } \\
\text { health both being treated together? }\end{array}$ \\
\hline 3 & How can we improve safe communication and coordination of care between primary and secondary care? \\
\hline 4 & In what ways does work intensity, hours worked and staffing levels affect patient safety/near misses? \\
\hline 5 & How does continuity of care influence patient safety? \\
\hline 6 & How well do patients understand the information that has been conveyed to them during the consultation? \\
\hline 7 & What can primary care do to identify and support people who may be at risk of suicide? \\
\hline 8 & $\begin{array}{l}\text { Which type of practitioner (general practitioner, advanced nurse practitioner, practice nurse) is safest to see which } \\
\text { types of patients (acute illnesses, acute or chronic multimorbid)? }\end{array}$ \\
\hline 9 & $\begin{array}{l}\text { How can information within patient medical records be made available to patients and care providers in a way that } \\
\text { protects privacy and improves safety and quality of care? }\end{array}$ \\
\hline 10 & How can risks be mitigated to allow for safe complex care at home? \\
\hline
\end{tabular}


example, Manchester was over-represented despite the engagement with national organisations to attempt to overcome this but from the demographic data collected we are unable to identify this. The breadth of different key stakeholders throughout the process was a strength, which ensured the credibility and relevance of the top 10 throughout the process. ${ }^{11} 3334$ However, the JLA procedure excludes non-clinical researchers, while including clinical researchers, ${ }^{9}$ assumes healthcare professional researchers are able to remove their research bias whereas non-clinical researchers (who may be users of primary care services as either patients or carers) are not. This approach has been adopted and supported by the NIHR, as it aims to redress the imbalance in setting the research agenda where wider voices have traditionally not been included (ie, patients and healthcare professionals) and while potentially all citizens are eligible to be users of primary care services, it was deemed appropriate to exclude those who may already influence priority setting through funding applications, research projects and other mechanisms.

One potential limitation of this process is the breadth of questions that were submitted, as primary care is a broad and diverse service area and some questions suggested large programmes of research (eg: "At what level can patient safety interventions in primary care be applied, eg, nationally, regionally, clinical commissioning groups, practice cluster, practice, individual clinician, patient?"). These questions were deliberately kept broad in order to ensure that questions kept the original intent of the submitted question in align with the JLA process. Rephrasing of indicative question were checked by the steering group to ensure that the original intent of the questions were maintained, but it was difficult in some circumstances to be able to focus the question to fit within a searchable criteria. The questions are generally broad, potential programmes of work which reflects the broad nature of the question focusing on a core component of service delivery rather than a specific disease focus. In these instances, we were as open and inclusive in the literature searching and reviewing as possible. Another strength of this approach was that the areas of priority from the initial open survey were reflected in the top 10 final priorities: communication, team and system working, interfaces across primary and secondary care, medication, self-management support and technology. One limitation of this study is that the majority of patients who completed the first survey were white (92\%) and over $55(58 \%)$ despite broad promotional activities. Information about sexual orientation was only collected at the first survey as it was not going to be used for analysis of the prioritisation results and in consultation with the steering group, it was decided not to collect the additional information to encourage engagement with the longer second survey. A consultation process like this will be more likely to reach people who were more engaged with research and this is a similar critique to the evaluations of other patient and public involvement activities who were more likely to involve white, older people. ${ }^{23}$ Engaging with black and minority ethnic groups across a range of ages is an important component of future work. Additionally, there was little engagement from younger adults and younger parents, as well as members from black and minority ethnic groups which was a limit of this work. Future work may need to use targeted engagement and involvement approaches to work with members of these groups and future PSPs could focus on identifying priorities for these communities.

\section{Future work}

This project will inform the development of future research priorities and funding applications. It is important that research in primary care patient safety prioritises questions that address practical issues to support care delivery and use. Future research could focus on understanding the priorities for particular communities, such as black and minority ethnic groups, who have often not participated in traditional research and patient and public involvement.

\section{Conclusions}

The top 10 primary care patient safety research priorities were generated using an established transparent and systematic approach. The research priorities covered a range of areas of priority for patients, carers and healthcare professionals; how patient safety can be assured for the most vulnerable in society, taking holistic approaches to care, transitions and communication of care between primary and secondary care, staffing issues, continuity of care, communication between patients and care providers, identifying and support people at risk of suicide, the appropriateness of different practitioners for different types of clinical work, accessing patient medical records and safe care at home. These findings will be used to address these issues to set the research agenda to support patients, carers and healthcare professionals and to maximise the utility and impact of patient safety research in primary care.

Acknowledgements The authors would like to thank all the participants who took part in the study and everyone who promoted the surveys. We would like to thank our JLA advisor, Richard Morley, for his guidance and advice and the JLA advisors who facilitated the final workshop. We would like to thank all of the steering group members for their support to steer and promote the PSP (surnames listed in alphabetical order): Rose Gallagher, Royal College of Nursing; Barry Kinshuck, British Dental Association; Alison Lea, Royal College of General Practitioners; Mike Molete, Healthwatch Manchester and Carers UK; Katherine Murphy, the Patients Association; Janice Perkins, Pharmacy Voice; Claire Vaughan, National Health Service Salford Clinical Commissioning Group; Mags Watson, Royal Pharmaceutical Society; and Laurence Webb, Lesbian, Gay, Bisexual and Trans Foundation. We would also like to thank the following information specialists for their help in running searches of the literature: Stephen Woods and Olivia Schaff from University Hospital of South Manchester library, and Elham Aalai and Michelle Dutton from Central Manchester Foundation Trust library.

Contributors SMC and ST designed the study and convened the steering group. RLM led the study, carried out data collection, analysis and interpretation of data. CR was responsible for promoting the surveys and coordinating members of the steering group. RA and SJS were involved in the data collection and interpretation. SWG and JW led the literature searching. RLM drafted the initial manuscript and all authors were involved in revising the manuscript and gave final approval of the 
version to be published. RLM is the guarantor. All authors, external and internal, had full access to all of the data (including statistical reports and tables) in the study and can take responsibility for the integrity of the data and the accuracy of the data analysis.

Funding The National Institute for Health Research Greater Manchester Primary Care Patient Safety Translational Research Centre (NIHR Greater Manchester PSTRC) funded this study.

Disclaimer The views expressed are those of the author(s) and not necessarily those of the NHS, the NIHR or the Department of Health.

Competing interests None declared.

Patient consent Not required.

Ethics approval The University of Manchester Research Ethics Committee approved the study (REC reference: 16141).

Provenance and peer review Not commissioned; externally peer reviewed.

Data sharing statement № additional data are available.

Open Access This is an Open Access article distributed in accordance with the Creative Commons Attribution Non Commercial (CC BY-NC 4.0) license, which permits others to distribute, remix, adapt, build upon this work non-commercially, and license their derivative works on different terms, provided the original work is properly cited and the use is non-commercial. See: http://creativecommons.org/ licenses/by-nc/4.0/

(c) Article author(s) (or their employer(s) unless otherwise stated in the text of the article) 2018. All rights reserved. No commercial use is permitted unless otherwise expressly granted.

\section{REFERENCES}

1. Spencer R, Campbell SM. Tools for primary care: a narrative review. BMC Fam Pract 2014;15:166.

2. Vincent C, Burnett S, Carthey J. The measurement and monitoring of safety. $2013 \mathrm{http}: / / \mathrm{www}$.health.org.uk/publications/themeasurement-and-monitoring-of-safety/.

3. Liberati A. Need to realign patient-oriented and commercial and academic research. Lancet 2011;378:1777-8.

4. Wilson T, Pringle M, Sheikh A. Promoting patient safety in primary care. BMJ 2001;323:583-4.

5. KingsFund. Improving the quality of care in general practice. 2011. https://www.kingsfund.org.uk/sites/files/kf/field/field_related document/gp-inquiry-report-evolving-role-nature-2mar11.pdf

6. Moher D, Glasziou P, Chalmers I, et al. Increasing value and reducing waste in biomedical research: who's listening? Lancet 2016;387:1573-86.

7. Tallon D, Chard J, Dieppe P. Relation between agendas of the research community and the research consumer. Lancet 2000;355:2037-40.

8. Crowe S, Giles $C$. Making patient relevant clinical research a reality. BMJ 2016;355:i6627.

9. NETSCC \& Cowan K. The James lind alliance guidebook. 2016. http://www.jla.nihr.ac.uk/jla-guidebook/downloads/JLA-GuidebookVersion-6-February-2016.pdf

10. Elwyn G, Crowe S, Fenton M, et al. Identifying and prioritizing uncertainties: patient and clinician engagement in the identification of research questions. J Eval Clin Pract 2010;16:631.

11. Wan YL, Beverley-Stevenson R, Carlisle D, et al. Working together to shape the endometrial cancer research agenda: The top ten unanswered research questions. Gynecol Oncol 2016;143:287-93.
12. Lloyd K, Rose D, Fenton M. Identifying uncertainties about the effects of treatments for schizophrenia. J Ment Health 2006;15:263-8.

13. Eleftheriadou V, Whitton ME, Gawkrodger DJ, et al. Future research into the treatment of vitiligo: where should our priorities lie? Results of the vitiligo priority setting partnership. $B J$ Dermatol 2011;164: 3:530-6.

14. NIHR. National research context. 2017 https://www.nihr.ac.uk/aboutus/our-purpose/national-research-context/.

15. INVOLVE. Exploring the impact of public involvement on the quality of research: examples. Eastleigh, UK: INVOLVE, 2013.

16. Chalmers I, Atkinson P, Fenton M, et al. Tackling treatment uncertainties together: the evolution of the James Lind Initiative, 2003-2013. J R Soc Med 2013;106:482-91.

17. Howick I, Chalmers P, Glasziou T, et al. Explanation of the 2011 Oxford Centre for Evidence-Based Medicine (OCEBM) levels of evidence. 2011. http://www.cebm.net/wp-content/uploads/2014/06/ CEBM-Levels-of-Evidence-Background-Document-2.1.pdf

18. NHS England. Your health and care records. 2017. http://www.nhs. uk/NHSEngland/thenhs/records/healthrecords/Pages/what_to_do. aspx

19. NHS England. $21 \%$ of patients in England can now access their medical record online. 2014. https://www.england.nhs.uk/2014/12/ patient-online-increase/

20. Patients Association. Seeing your medical records. 2017. https:// www.patients-association.org.uk/wp-content/uploads/2017/08/ Seeing-your-medical-records.-1.pdf

21. ABPI. New partnership set to help 'transform' access to medicines for patients in Greater Manchester. 2017. http://www.abpi.org.uk/ media-centre/newsreleases/2017/Pages/New-partnership-set-tohelp-\%E2\%80\%98transform $\%$ E2\%80\%99-access-to-medicinesfor-patients-in-Greater-Manchester-24.02.17.aspx

22. Chalmers I, Glasziou P. Avoidable waste in the production and reporting of research evidence. The Lancet 2009;374:86-9.

23. Redwood S, Gill PS. Under-representation of minority ethnic groups in research--call for action. Br J Gen Pract 2013;63:342-3.

24. NICE. Improving health and social care through evidence-based guidance. 2017. https://www.nice.org.uk/

25. Moffat K, Mercer SW. Challenges of managing people with multimorbidity in today's healthcare systems. BMC Fam Pract 2015;16:129.

26. Morris RL, Sanders C, Kennedy AP, et al. Shifting priorities in multimorbidity: a longitudinal qualitative study of patient's prioritization of multiple conditions. Chronic IIIn 2011;7:147-61.

27. Tarrant C Windridge K Boulton M, et al. Qualitative study of the meaning of personal care in general practice. BMJ 2003;326:1310.

28. Wilson T, Roland M, Ham C. The contribution of general practice and the general practitioner to NHS patients. J R Soc Med 2006;99:24-8.

29. Rhodes P, McDonald R, Campbell S, et al. Sensemaking and the co-production of safety: a qualitative study of primary medical care patients. Sociol Health IIIn 2016;38:270-85.

30. Grimshaw JM, Eccles MP, Lavis JN, et al. Knowledge translation of research findings. Implement Sci 2012;7:50.

31. Panesar SS, deSilva D, Carson-Stevens $A$, et al. How safe is primary care? A systematic review. BMJ Qual Saf 2016;25:544-53.

32. Wynia MK, Classen DC. Improving ambulatory patient safety: learning from the last decade, moving ahead in the next. JAMA 2011;306:2504-5.

33. Bryant J, Sanson-Fisher R, Walsh J, et al. Health research priority setting in selected high income countries: a narrative review of methods used and recommendations for future practice. Cost Eff Resour Alloc 2014;12:23.

34. Sibbald SL, Singer PA, Upshur R, et al. Priority setting: what constitutes success? A conceptual framework for successful priority setting. BMC Health Serv Res 2009;9:43. 